\title{
Obesity and Altered Body Composition in Childhood ALL Survivors
}

\section{Introduction}

Survivors of childhood leukemia are at increased risk for obesity, insulin resistance and metabolic syndrome. BMI is only a crude indicator of body $\mathrm{fat}^{(1)}$. The amount of fat and lean body mass are important risk factors for the prediction of cardiovascular disease and type $2 \mathrm{DM}^{(2)}$. Lipid partitioning is much more related to the metabolic phenotype of obese children and adolescents than the degree of obesity ${ }^{(3)}$

\section{Objectives}

to assess frequency of obesity and metabolic syndrome in childhood ALL survivors and to study the alteration in their body composition. - To identify risk factors associated with obesity and MS in survivors of childhood ALL.

\section{Subjects \& Methods}

Twenty-nine childhood ALL survivors were enrolled (mean age 14.4 \pm 3.4 years) from Pediatric Oncology Clinic at Ain Shams University Children's Hospital. Six patients had received cranial radiotherapy, and median time from end of therapy was 43.9 months. Thirty healthy subjects were enrolled as a control group.

- We evaluated anthropometric measurements including weight, height, BMI, waist circumference, hip circumference and waist-tohip ratio. Body composition was analyzed using Tanita SC-330P scale.

Measurement of fasting insulin, glucose, lipids and serum leptin was done for all participants.

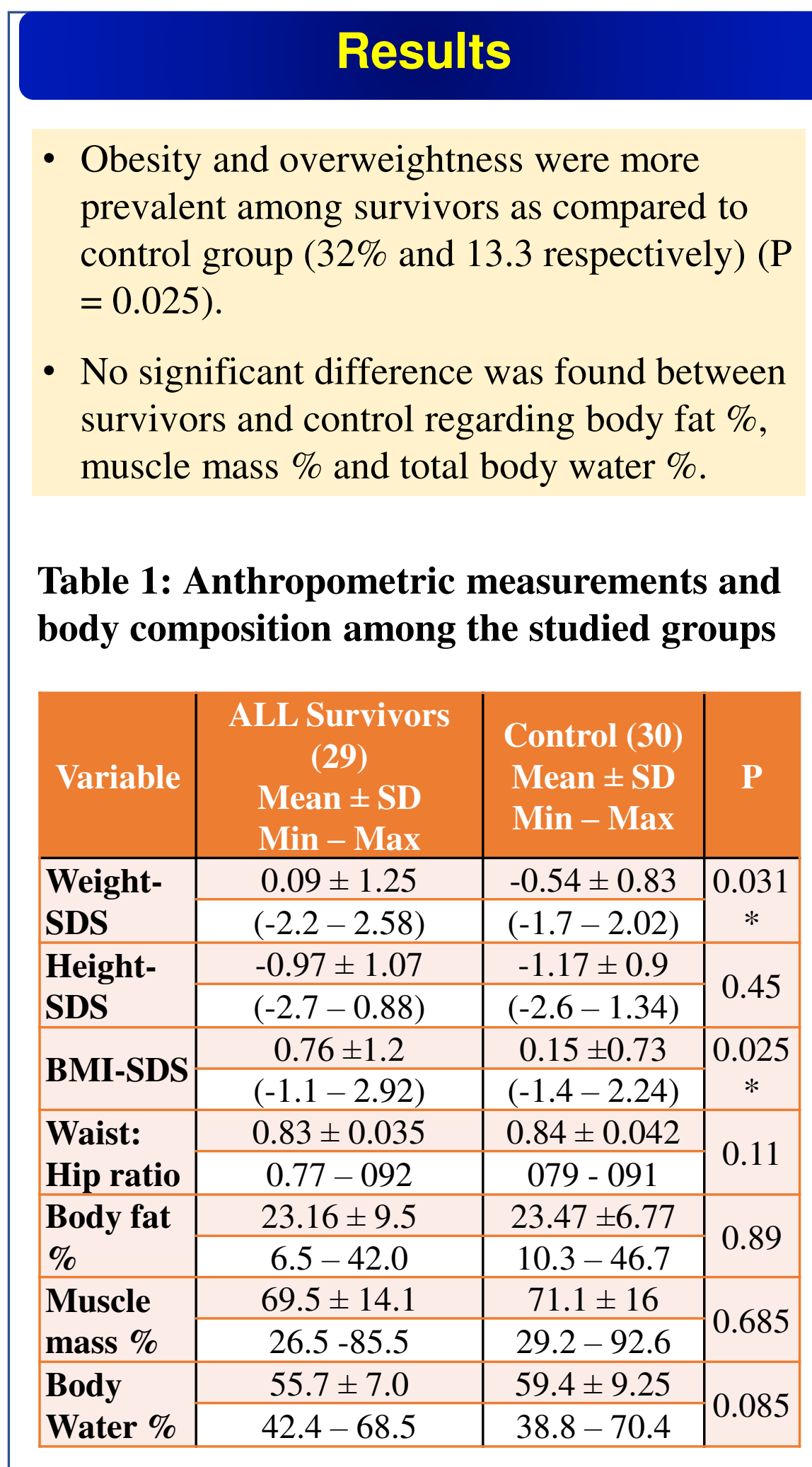

- ALL survivors had significantly higher levels of serum leptin $(\mathrm{P}=0.02)$ and total cholesterol $(\mathrm{P}=0.03)$, but LDL-C, HDL-C and triglycerides were comparable in both groups.

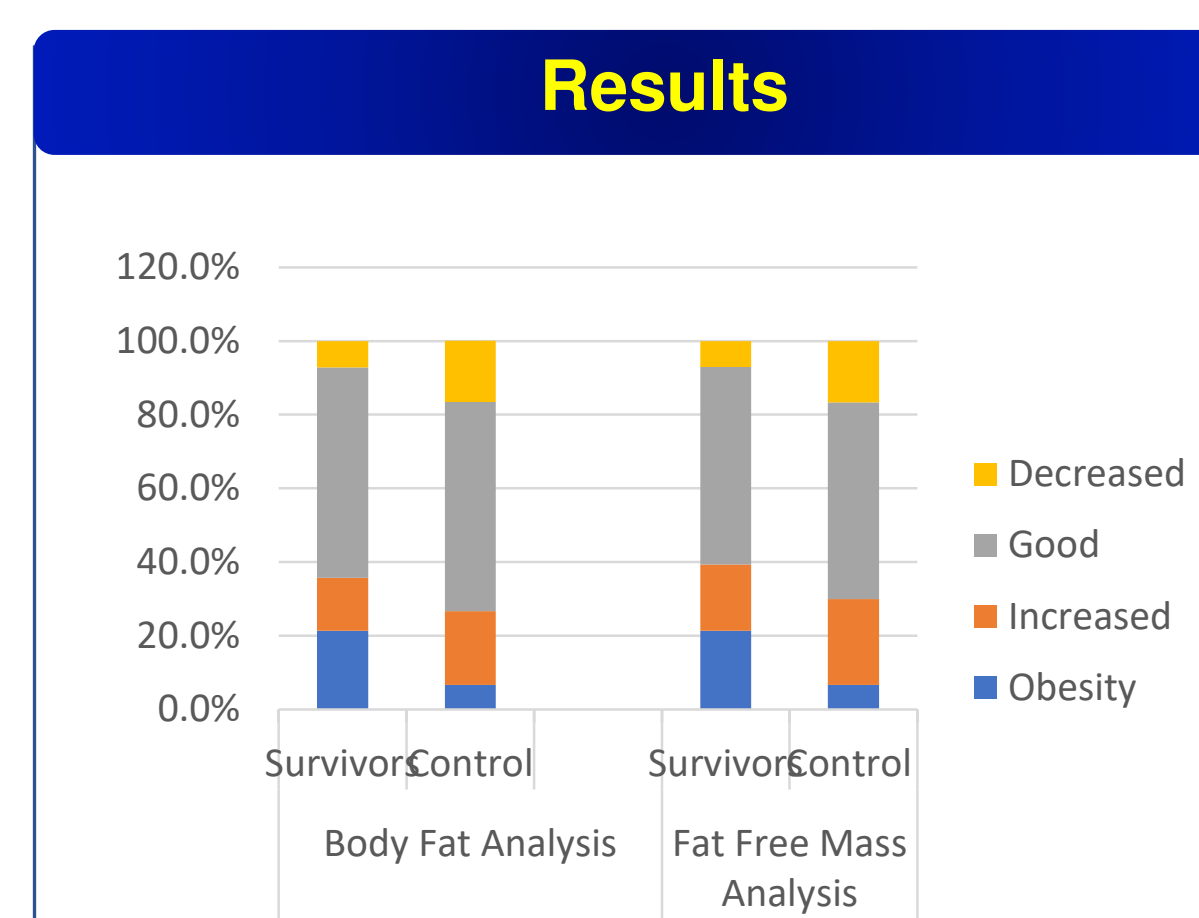

Figure 3: Body Fat and Fat free mass analysis among ALL survivors versus healthy controls.

Table 1: Anthropometric measurements and body composition among the studied groups

\begin{tabular}{c|c|c|c|c}
\multicolumn{1}{|c|}{ Variable } & & $\begin{array}{c}\text { Survivors } \\
\text { No. }=29\end{array}$ & $\begin{array}{c}\text { Control } \\
\text { No. =30 }\end{array}$ & P \\
\cline { 1 - 4 } $\begin{array}{l}\text { Serum Leptin } \\
\text { (ng/ml) }\end{array}$ & Median & 5.25 & 3.0 & \multirow{2}{*}{0.02} \\
\cline { 2 - 4 } & IQR & $(1.3-8.0)$ & $\begin{array}{c}(0.5- \\
11.5)\end{array}$ & \\
\hline
\end{tabular}

- Among the survivor group, time since end of therapy was the only identified risk factor between patients with normal versus abnormal BMI; being significantly higher in the overweight/obese group $(\mathrm{P}<0.001)$

- Other factors including age at diagnosis, age at study entry, gender, IPT, mean duration of therapy and the use of cranial irradiation did not differ between both groups.

Overweight/obese survivors had significantly higher body fat $\%(\mathrm{P}<0.001)$, lower muscle mass \% $(\mathrm{P}=0.014)$ and TBW \% $(\mathrm{P}<0.001)$.

\section{Results}

Table 2: Body composition analysis among ALL survivors with normal versus abnormal BMI

\begin{tabular}{|c|c|c|c|}
\hline Variable & $\begin{array}{l}\text { Normal BMI } \\
\text { ALL (19) } \\
\text { Mean } \pm \text { SD } \\
\text { Min - Max }\end{array}$ & $\begin{array}{c}\text { Abnormal BMI } \\
\text { ALL (9) } \\
\text { Mean } \pm \text { SD } \\
\text { Min - Max }\end{array}$ & $\mathbf{P}$ \\
\hline \multirow{2}{*}{ WC (cm) } & $74 \pm 8.3$ & $87.5 \pm 12.1$ & \multirow{2}{*}{$0.007 *$} \\
\hline & $62-$ & $77-110$ & \\
\hline $\mathrm{HC}(\mathbf{c m})$ & & & $0.018 *$ \\
\hline \multirow{2}{*}{$\begin{array}{l}\text { Waist: } \\
\text { Hip ratio } \\
\text { Body fat } \\
\%\end{array}$} & & & $0.001^{*}$ \\
\hline & $\begin{array}{l}17.8 \pm 5.7 \\
6.5-25.5\end{array}$ & & $<0.001 *$ \\
\hline $\begin{array}{l}\text { Muscle } \\
\text { mass \% }\end{array}$ & $\begin{array}{l}72.9 \pm 16.0 \\
26.5-88.6\end{array}$ & $\begin{array}{c}62.4 \pm 4.6 \\
55-66.8\end{array}$ & $0.014 *$ \\
\hline $\begin{array}{l}\text { Body } \\
\text { Water \% }\end{array}$ & $\begin{array}{c}59.4 \pm 4.6 \\
51-68.5\end{array}$ & $\begin{array}{l}47.7 \pm 3.9 \\
42.4-51.6\end{array}$ & $<0.001^{*}$ \\
\hline
\end{tabular}

\section{Conclusion}

Childhood ALL survivors are more prone to obesity, altered body composition and hyperlipidemia, and hence increased risk of developing metabolic syndrome. Incorporating preventive strategies into treatment regimens may be needed to prevent early development of these metabolic abnormalities.

\section{References}

1.Jarfelt et al 2005. Body composition in young adult survivors of childhood acute lymphoblastic leukaemia. Eur J Endocinol 153(1): 81-9.

2. Sohn et al 2011. The metabolic syndrome and body composition in childhood cancer survivors. Korean J Pediatr 54(6): 253-9. children and adolescents. N Engl J Med 350(23): 2362-74. 